experience of the past three years at the National Bureau of Standards is therefore a useful pointer to the problems of operating a thoroughly ambitious data system, and to some potential solutions as well.

There is no question that the plans of the National Standard Reference Data System are ambitious-and events may yet show that they have outstripped the budget. The physical sciences have been partitioned into seven fields, and separate programmes are under way in each of them. Only in nuclear physics do the existing arrangements approximate to what is thought necessary, so that the National Bureau of Standards can confine itself to the evaluation of data on elementary particles and cosmic rays. In other fields, several new projects have been started, sometimes within the Bureau of Standards but also frequently by letting contracts to independent organizations-universities, government laboratories and sometimes commercial organizations. Not surprisingly, activity is most conspicuous in thermodynamics and atomic and molecular spectra. Although the general field of "mechanical properties" is included in the brief for the reference data system, it will be hard to begin to make a start in this jungle, partly because of the difficulty of deciding what kind of information would be of value to potential users, partly because of the sheer bulk of it, and partly because of the way in which information about the mechanical properties of materials tends to depend on the method of measurement.

There is also the problem which has traditionally beset the compilers of critical tables-the frequently invidious task of deciding which published data to trust. The National Standard Reference Data System acknowledges that, in the last resort, value judgments of this kind cannot be left to machines. This is why it is good to see how it has been possible to encourage academic interest in the evaluation of data by the judicious letting of contracts. Elsewhere, scientists are still more eager to give their blessing to plans for collecting data than to undertake to carry out some of the hard work involved. But compilation is only half the story. There is also to be a huge effort on dissemination. The first of what will be a torrent of volumes of critical data have already appeared. At some stage, possibly within three or five years, a computer system will permit faster access to the files, and there will be a fast and comprehensive system by means of which individual laboratories will have access not merely to the computer files in Washington but to those in associated data centres as well.

\section{Science Teaching Centre}

The Chelsea College of Science and Technology in London has announced a plan to create a centre intended to make a continuing contribution towards research in teaching methods in science. In a statement issued last week the principal of the College, Dr. M. R. Gavin, says that the College has in mind the possibility that there may be a hiatus in the development of new. science curricula for British schools when the current plans of the Nuffield Foundation Science Teaching Project are worked out at the end of this decade. The College hopes to be able to be ready, before then, to play a full part in the development of methods of teaching science, and intends to cut its teeth in a number of fields of research and development ranging from the development of new curricula to the design of equipment and apparatus. The statement makes the point that such a centre would complement work in teacher training in a particularly valuable way, and that it would also serve as a means of providing teachers in the Greater London area with opportunities for in-service training. The first academic appointments will be made for the academic year immediately ahead. The College is evidently hoping that its plans for creating a centre for teaching science at Chelsea will match well with the secondment of the head of the Physics Department at Chelsea, Professor K. W. Keohane, to the Nuffield Foundation Science Teaching Project from July this year.

\section{Chemical Research, Melbourne}

DR. A. L. G. ReEs, chief of the Division of Chemical Physics, C.S.I.R.O. Chemical Research Laboratories, Melbourne, Australia, writes:

"A new laboratory for the Division of Chemical Physics has now been opened at Melbourne by Senator J. G. Gordon, minister in charge of C.S.I.R.O. The building has been named the David Rivett Laboratory after the late Sir David Rivett, for nearly 20 years chief executive officer and later chairman of the C.S.I.R.O. Sir David, a physical chemist, actively promoted the establishment of research in chemical physics in 1944 and encouraged its rapid development.

"The first steps taken in 1944 involved the establishment of specialized groups concerned with physical techniques and their application to chemical problems. Current sections include spectroscopy, electron and $\mathrm{X}$-ray diffraction, electron microscopy, solid state and theoretical chemistry, and instruments and engineering services. The Division pioneered electron microscopy in Australia; its first work was largely on problems oriented towards biology. Early work on the fine histology of wool stimulated a more general interest. in fibrous proteins. The Division entered the related field of electron diffraction in 1945 and its first task was the development of electron diffraction apparatus.

"Research in mass spectroscopy has been conducted in the Division since 1947. The major theme has been the elucidation, by experimental and theoretical methods, of the behaviour of molecules under electron and photon bombardment. In solid state chemistry, studies have been oriented towards establishing the significance of crystal defects in chemical behaviour The occupation of new premises has allowed the expansion of research in this area, the most important of which concerns the low-temperature thermodynamic studies of non-stoichiometric solids.

"From the beginning, considerable attention has been paid to technique and instrumentation in chemical physics research, with the result that new techniques and new instruments have appeared as by-products. A number of these have encouraged the rapid development of the manufacture of scientific instruments in Australia. The most successful example to date is the manufacture of spectroscopic instruments. The total value of such equipment now produced each year in Australia exceeds one million Australian dollars."

\section{Centres for Engineering}

ENGINEERING education and training in Britain will have to be overhauled if it is to attract its fair share 